\title{
Knowledge on Handling of HIV and HBV Patients and Occupational Post- Exposure Prophylaxis against HIV and HBV: Effectiveness of Training Programme for Nurses
}

\author{
Abha Sharma*, Bibhabati Mishra, Vinita Dogra, Archana Thakur and Poonam Sood Loomba \\ GB Pant Institute of Post Graduate Medical Education and Research, New Delhi, India \\ *Corresponding author: Abha Sharma, GB Pant Institute of Post Graduate Medical Education and Research, New Delhi, India, Tel: 7042244066; E-mail: \\ abha_sh79@rediffmail.com
}

Received date: May 03, 2018; Accepted date: Jan 30, 2019; Published date: Feb 07, 2019

Copyright: $\odot 2019$ Sharma A, et al. This is an open-access article distributed under the terms of the Creative Commons Attribution License, which permits unrestricted use, distribution, and reproduction in any medium, provided the original author and source are credited.

\begin{abstract}
Background: During the course of health care of patients, thousands of health care workers suffer occupational exposures among which nurses have high chances of exposure to blood-borne pathogens as they are the primary health care providers to patients in hospitals. Post-exposure prophylaxis has become routine following the occupational exposure of HCWs to HIV and HBV. So it is important that nurses keep their knowledge updated regarding handling of HIV and HBV patients and how to manage occupational exposure.
\end{abstract}

Method: A training programme for nurses was conducted by a tertiary care hospital and their knowledge regarding occupational exposure management and handling of HIV and HBV patients was assessed through pretest and post-test questionnaire.

Result: Total 36 clinically registered nurses participated. The mean score of pre-test was 8.7 which increased to 10.1 in post-test. The knowledge related to PEP and handling of HIV and HBV patients improved significantly after the training class $(p=0.0001$ and 0.002 respectively).

Conclusion: The nurses are quite prone for occupational exposure to HIV and HBV and the findings of this study highlight the importance of continuous training of nurses so that they have a comprehensive understanding of PEP and standard precautions. Thorough orientation to the PEP procedure will help them access appropriate medical advice in a timely manner.

Keywords: PEP; Nurses; Handling HIV and HBV patients; Standard precautions

\section{Introduction}

Health care workers (HCWs) are constantly at risk of occupational exposure to blood borne pathogens especially HIV (Human immunodeficiency virus) and HBV (Hepatitis B virus) via needle stick injuries, percutaneous /mucosal/ non-intact skin contact with blood and body fluid [1]. 2.5\% of HIV cases and 40\% HBV and HCV (Hepatitis $\mathrm{C}$ virus) are due to occupational exposure among HCWs as reported by WHO [2]. The risk of transmission of HIV is $0.3 \%$, after exposure to HIV-infected blood while it is much more (100 times) for $\mathrm{HBV}$ [3]. The prevalence of HBV and HIV in India is $2.4 \%-15.9 \%$ and $0-35 \%$ respectively $[4,5]$. As nurses are the frontline providers of healthcare, they represent the greatest proportion of exposed HCWs who take care of patients with HIV and HBV infection [6]. HCWs have a significant role in the prevention and management of HIV and HBV infected patients. There are many opportunities when HCWs, especially nurses, provide information to patients and their attendants regarding behavior changes that are required to prevent the spread of these infectious diseases. Therefore, it is essential that nurses should have adequate knowledge about Post Exposure Prophylaxis (PEP) and risk of transmission of HIV and HBV after occupational exposure to blood and body fluids. Thus training is an important interventional measure to protect them from professional exposure to HIV and HBV infections. Studies from other countries suggest that a lack of knowledge and negative attitudes among HCWs may serve as barriers to provide effective health education and disease management of these infectious diseases CDC recommends that nurses and all HCWs should follow universal precautions which are a set of important guidelines like use of Personal Protective Equipments (PPE)-gloves, masks, gowns etc. to protect patients and HCWs from exposure to blood borne pathogens [7]. In 1996, the healthcare infection control practices advisory committee (HICPAC) formulated certain revised guidelines, termed 'standard precautions', which included all major features of universal precautions and body substance isolation precautions to be taken for all patients at all times [8]. It is also important to assess the handling of HIV and HBV patients by the nurses. Various studies have shown that negative attitude and lack of knowledge among HCWs serves as a key barrier in the proper management of such patients $[9,10]$. In resource limited settings where the burden of HIV and HBV infections is huge, the data regarding occupational exposure and use of personal protective equipment's (PPE) is limited. Many a times there PPE and safe devices are not available for use and proper sharp disposal methods are not followed. All these factors pose a high risk for the nurses working in such settings to occupational exposures. Few studies are available addressing the issues of occupational exposures and handling of HIV and HBV patients by nurses from developing countries. The present 
Citation: Sharma A, Mishra B, Dogra V, Thakur A, Loomba PS (2019) Knowledge on Handling of HIV and HBV Patients and Occupational PostExposure Prophylaxis against HIV and HBV: Effectiveness of Training Programme for Nurses. J Nurs Care 8: 471 . doi: $10.4172 / 2167-1168.1000471$

Page 2 of 4

study was conducted with the aim of studying the existing knowledge of nurses about HIV and HBV patient care and effectiveness of a training programme as an intervention to improve patient care as well as reduce occupational exposure incidences.

\section{Method}

\section{Setting and participants}

The study was conducted in a super speciality hospital which is a post graduate Institute at New Delhi after taking approval from the ethical and research committee of the Institute. A training programme was organized by the hospital specifically targeting the nurses working in tertiary care setting. The participants were clinical registered nurses working across various tertiary care hospitals in Delhi. Out of the total 36 clinically registered nurses who participated in the training programme, 23 were from same institute and 13 were from different institutes.

\section{Study procedure, data collection and analysis}

A self-administered pre-test questionnaire was developed. The questionnaire was used to test the knowledge related to handling of HIV and HBV patients and Post Exposure Prophylaxis (PEP) of HIV and HBV. All the participants answered the pre-test questionnaire. Their identity was kept anonymous. Then a training class was taken for all the nurses about handling of HIV and HBV patients and PEP against HIV and HBV, with the goal to increase their knowledge about HIV/HBV. The session included a power point presentation on standard precautions and PEP management of HIV and HBV, followed by discussion of case studies in small groups of 5-6 members each measuring their attitude as regards caring for individuals with HIV and HBV and management of occupational exposures. The session concluded with a knowledge contest (quiz). Participants were asked to share their experiences while caring for HIV and HBV patients. A post-test questionnaire was filled up by the participants. All questions in pre-test questionnaire were repeated in the post-test questionnaire. For questions related to PEP, the participants were supposed to choose the right answer and for questions related to handling of HIV and HBV patients, the participants had to agree or disagree. Improvement in knowledge was assessed by making a comparative analysis of the correct responses before and after the training class. For scoring, one mark was allotted to correct answer and zero to incorrect answer. Percentage of all correct answers before and after the training were calculated and compared. Statistical analysis was done by using the ${ }^{\odot}$ 2018 Graphpad software, manufactured in San Diego, California. Fisher's exact test was used to calculate significant $P$ value $(<0.05)$.

\section{Result}

A total of 36 nurses participated in the training programme. All of them answered the pre-test and post-test questionnaire. The mean score of pre-test was 8.7 which increased to 10.1 in post-test. Out of the 36 , only 5 participants had experienced needle stick injury/ occupational exposure to blood and body fluids. Three of them had followed hand washing with soap and water immediately after exposure while one of them first reported to the concerned authorities while one of them first took the patient for testing for HIV and HBV. Table 1 and 2 depicted the comparative analysis of correct answers before and after training class. The knowledge related to PEP and handling of HIV and HBV patients improved significantly after the training class ( $\mathrm{p}=0.0001$ and 0.002 respectively).

Nurses' awareness and knowledge regarding infectious body fluids and PEP (Table 1) significantly improved after the post test. They had become more aware about standard precautions and the importance of hand hygiene. Their knowledge on HIV infection and its transmission and HIV patient care improved significantly (Table 2).

\begin{tabular}{|c|c|c|c|}
\hline \multirow[t]{2}{*}{ Question (correct answer) } & $\begin{array}{l}\text { Correct answers } \\
\mathrm{N}(\%)\end{array}$ & $\begin{array}{l}\text { Correct answers } \\
\mathrm{N}(\%)\end{array}$ & \multirow[t]{2}{*}{$P$ value } \\
\hline & Before training $\mathrm{N}=36$ & After training $\mathrm{N}=36$ & \\
\hline What is the percentage transmission of HIV and HBV owing to needle stick injury? & $20(55)$ & 22(61) & 0.8113 \\
\hline $\begin{array}{l}\text { A nursing student sustains a needle stick injury from a HBV positive intravenous drug user. } \\
\text { Regarding Hepatitis B which of the following statements is true? }\end{array}$ & $26(72)$ & $30(83)$ & 0.3957 \\
\hline PEP (Post Exposure Prophylaxis) should be started ideally & 10(28) & $35(97)$ & $0.0001^{*}$ \\
\hline $\begin{array}{l}\text { According to the BMW management } 2016 \text { guidelines, sharps are to be discarded in which color } \\
\text { coded container }\end{array}$ & $27(75)$ & $29(80)$ & 0.775 \\
\hline $\begin{array}{l}\text { In case of needle stick injury, cut, or fluid contact with nonintact skin, the first step to minimize } \\
\text { risk of transmission is }\end{array}$ & $36(100)$ & $36(100)$ & 1 \\
\hline All of the body fluids are considered potentially infectious except & 14(39) & $29(80)$ & $0.0006^{*}$ \\
\hline $\begin{array}{l}\text { Discarded needle, devices/instruments should be tested for HIV in case of needle stick injury or } \\
\text { body fluid exposure }\end{array}$ & $16(45)$ & $29(80)$ & $0.0031^{*}$ \\
\hline Pregnancy is a contraindication for PEP & $28(78)$ & $35(97)$ & $0.0278^{*}$ \\
\hline
\end{tabular}

Table 1: Comparative analysis of correct responses to different questions in the questionnaire before and after training regarding Post exposure prophylaxis (PEP). 
Citation: Sharma A, Mishra B, Dogra V, Thakur A, Loomba PS (2019) Knowledge on Handling of HIV and HBV Patients and Occupational PostExposure Prophylaxis against HIV and HBV: Effectiveness of Training Programme for Nurses. J Nurs Care 8: 471. doi: 10.4172/2167-1168.1000471

Page 3 of 4

\section{Discussion}

Nurses working in hospital settings encounter a lot of challenges in dealing with the HIV and HBV patients due to the high workload, staff shortage, lack of basic patient care items and PPE etc. Many a times they are also not vaccinated against HBV. In present study, we found that most of the nurses i.e. (60-70\%) had knowledge about the standard precautions and PEP as detected by pre-test, which significantly improved after training to $85-90 \%$. Regarding the participant's knowledge about PEP, $<50 \%$ had the knowledge about the ideal timing of starting of PEP and which body fluids are to be considered as potentially infectious. After the training class, this knowledge significantly improved and $>80 \%$ nurses gave the correct answer $(\mathrm{p}=0.001)$ as to the ideal timing of starting PEP and what potentially infectious body fluids are $(\mathrm{p}=0.0006)$. This finding is concordant with another study done in China in 2016 [11] where before intervention $28 \%$ HCWs knew the ideal timing of starting PEP and which further increased to $50 \%$ after intervention while $70 \%$ who knew about infectious body fluids their knowledge increased to $80 \%$ after intervention. In another study in Bharatpur from India, $60 \%$ of the HCWs knew that the best time to start PEP is within 2 hours of occupational exposure [12].
Out of 36 participants, 5 nurses shared their experience of occupational exposure. Their exposure was mainly due to sharps or a needle stick injury. Three out of them had washed the site of exposure immediately with soap and water. Due to panic reaction, one out of them first reported the incident to the concerned authorities and the other took the patient's sample first, for testing for HIV and HBV although both these nurses were aware of the first aid management after exposure. Most of the nurses $(>70 \%)$ were aware of the fact that $\mathrm{HBV}$ vaccine is routinely available to HCWs and they all should be vaccinated in their hospital set up so they got themselves vaccinated. All the nurses were even aware of their antibody titres against HBV. All of them (100\%) knew that the first step to minimize risk of infection after exposure is washing the site with soap and water. In contrast to present study, Dhital et al. [12] in their study found that only $39.39 \%$ of nurses had the knowledge of first aid management after getting needle stick injury. Surprisingly $<50 \%$ knew that discarded needle, device/ instruments should not be tested for HIV/HBV after exposure. However, post-training the level of knowledge improved significantly $(\mathrm{p}=0.0031)$ as $80 \%$ had answered the questions correctly. More than $50 \%$ were aware that pregnancy is not a contraindication for PEP. They also knew the percentage transmission of HIV/HBV in needle stick injury and the correct method of sharp disposal.

\begin{tabular}{|l|l|l|l|}
\hline Questions (correct answer) & $\begin{array}{l}\text { Correct answers } \\
\text { N (\%) }\end{array}$ & $\begin{array}{l}\text { Correct answers } \\
\text { N (\%) }\end{array}$ & P value \\
\cline { 2 - 3 } & $\begin{array}{l}\text { Before training } \\
\text { N (\%) }\end{array}$ & $\begin{array}{l}\text { After } \\
\text { (\%) }\end{array}$ \\
\hline training N \\
\hline Hand washing is the first priority in preventing infections when providing care for a patient. & $33(92)$ & $36(100)$ & 0.2397 \\
\hline Standard precautions should only be used in patients diagnosed with infection. & $26(72)$ & $32(89)$ & 0.1348 \\
\hline Gloves should be changed between cares of different patients. & $28(78)$ & $34(94)$ & 0.0847 \\
\hline $\begin{array}{l}\text { Patients who are infected with HIV should not be treated in the same area as other patients in order to } \\
\text { protect them from infection. }\end{array}$ & $34(94)$ & $34(94)$ & 1 \\
\hline Total correct answers and rate (total answers of pre-test $36 \times 5=180$ and post-test= 36X5=180) & $32(89)$ & $0.0130^{*}$ \\
\hline Significant $P$ value $=<0.05$ & $143(79.4)$ & $168(93.3)$ \\
\hline
\end{tabular}

Table 2: Comparative analysis of correct responses to different questions in the questionnaire before and after training regarding handling of HIV and HBV positive patients.

There was significant improvement $(\mathrm{p}=0.0002)$ regarding the knowledge about handling of HIV/HBV infected patients. Their previous knowledge on hand hygiene was extremely good as $90 \%$ nurses knew that hand washing is the first priority in preventing infections. The nurses were well aware of standard precautions. All of them $(100 \%)$ were aware of the fact that gloves should be changed between cares of different patients. The correct knowledge regarding route of transmission of HIV and HBV was $60 \%$ before training which significantly improved $(\mathrm{p}=0.0130)$ to $89 \%$. The nurses became aware that HIV infected patients do not need isolation unless until they have some co-infection which may require isolation/transmission based precaution.

Since the burden of HIV/HBV infection in India is huge with increasing prevalence, nursing personnel are more prone to be at risk and lack of knowledge and training will further place the nurses at risk for occupational exposure. Therefore, regular interventions by conducting training programmes are essential for occupational safety. A study $[13,14]$ showed that $62-88 \%$ of the needle stick injuries can be prevented through technology and training. In another study in Iran by Joukar et al., $52 \%$ of the HCW participants had unsatisfactory knowledge regarding $\mathrm{HCV}$ and $\mathrm{HBV}$ and they recommended that In service training about universal and standard precaution and also improvement in work condition can decrease the probable risk for health professional [15].

Updating the knowledge about standard precautions on a regular basis, safe injection practices, proper sharp disposal and PEP are effective measures in preventing occupational exposures among the nurses. Study done by Ishimaru et al. in Vietnam suggested that confidence in protecting oneself against infection was a positive factor associated with willingness to care for patients infected with HIV or HBV/HCV. A positive safety culture, such as strict infection control, not only protects healthcare workers but also improves the quality of 
Citation: Sharma A, Mishra B, Dogra V, Thakur A, Loomba PS (2019) Knowledge on Handling of HIV and HBV Patients and Occupational PostExposure Prophylaxis against HIV and HBV: Effectiveness of Training Programme for Nurses. J Nurs Care 8: 471 . doi: 10.4172/2167-1168.1000471

Page 4 of 4

patient care [16]. A well designed training programme implemented in this study included appropriate training content, lecture with group discussions, case studies to deal with different situations along with pre and post-test. A quiz contest in the end encouraged the nurses to recall all important facts about PEP and handling of HIV/HBV patients. Thus, present training session showed statistically significant improvement in the overall knowledge of nurses.

\section{Conclusion}

Understanding the attitude and knowledge of Nurses towards patients with HIV and HBV is the first step in improving health education and health care services. This study helps to develop interventions for HIV, HBV and HCV-related knowledge and attitudes for HCWs, which further will guide prevention strategies for HIV, HBV and HCV infection. It is recommended that more studies should be conducted at a larger scale, to assess the effectiveness of training interventions on occupational safety.

\section{References}

1. Hadadi A, Karbakhsh M, Rasoonlinejad M, Abdolbaghi MH, Hadadi N, et al. (2013) Post Exposure prophylaxis against HBV and HIV infection in health care workers. Adv Infect Dis 3: 193-199.

2. World Health Report (2002) Reducing risk, promoting healthy life, WHO, Geneva.

3. Canadian Centre for Occupational Health and Safety (CCOHS) (2005). Needle stick injuries.

4. Batham A, Naura D, Toteja T, Sreenivas V, Puliyel JM (2007) Systematic review and meta-analysis of prevalence of hepatitis $\mathrm{B}$ in India. Indian Paediatr 44: 663-674.

5. National AIDS Control Organization Govt. of India, Annual report 2013-2014.
6. Chen WT, Han M (2010) Knowledge, attitudes, perceived vulnerability of Chinese nurses and their preference for caring for HIV-positive individuals: A cross-sectional survey. J Clin Nurs 19: 3227-3234.

7. Centers for Disease Control and Prevention (1988) Update: Universal Precautions for prevention of transmission of HIV, Hepatitis B and other blood borne pathogens in health care settings. MMWR Morb Mortal Wkly Rep 37: 377-382.

8. Garner JS (1996) Guidelines for isolation precaution in hospitals. The hospital infection control practices Advisory Committee. Infect Control Hosp Epidemiol 17: 53-80.

9. Birhanu Z, Abdissa A, Belachew T, Deribew A, Segni H, et al. (2012) Health seeking behaviour for cervical cancer in Ethiopia: A qualitative study. Int J Equity Health 11: 83.

10. Liese B, Dussault G (2004) The state of the health workforce in subsaharan Africa : Evidence of crisis and analysis of contributing factors. Africa region Human development working paper series. Africa region the world bank, Washington.

11. He L, Lu Z, Huang J, Zhou Y, Huang J, et al. (2016) An integrated intervention for increasing clinical nurses' knowledge of HIV/AIDSrelaated occupational safety. Int J Environ Res Public Health 13: 1094.

12. Dhital PS, Sharma S, Poudel P, Dhital PR (2017) Knowledge regarding PEP of HIV among nurses. Nursing: Research and Reviews 7: 45-50.

13. OSHA (2001) Occupational exposure to blood borne pathogens, needle stick and other sharp injuries: Final rule. Fed Regis 66: 5318-5325.

14. Mtengezo J, Lee H, Ngoma J, Kim S, Aronowitz T, et al. (2016) Knowledge and attitudes toward HIV, hepatitis B virus, and hepatitis C virus infection among health-care workers in Malawi. Asia Pac J Oncol Nurs 3: 344-351.

15. Joukar F, Mansour-Ghanaei F, Naghipour MR, Hasandokht T (2017) Nurses' Knowledge toward Hepatitis B and Hepatitis C in Guilan, Iran. Open Nurs J 11: 34-42.

16. Ishimaru T, Wada K, Hoang HTX, Bui ATM, Nguyen HD, et al. (2017) Nurses' willingness to care for patients infected with HIV or Hepatitis B/C in Vietnam. Environ Health Prev Med 22: 9. 